Original Research

\title{
Characterization of Luteal Blood Flow and Secretion of Progesterone in Mares Treated With Human Chorionic Gonadotropin for Ovulation Induction or During Early Diestrus
}

\author{
Rafael Mide Romano a Jair Camargo Ferreira ${ }^{a, b}, *$, Heloisa de Siqueira Canesin ${ }^{\text {a }}$, \\ Yatta Linhares Boakari ${ }^{a}$, Fernanda Saules Ignácio ${ }^{a}$, Luiz Fernando Novaes Filho ${ }^{\text {, }}$ \\ Donald L. Thompson Jr. ${ }^{\mathrm{b}}$, Cezinande de Meira ${ }^{\mathrm{a}}$ \\ ${ }^{a}$ Department of Animal Reproduction and Veterinary Radiology, School of Veterinary Medicine and Animal Science, UNESP, Botucatu, SP, Brazil \\ ${ }^{\mathrm{b}}$ School of Animal Sciences, Louisiana State University Agricultural Center, Baton Rouge, LA
}

\section{A R T I C L E I N F O}

\section{Article history:}

Received 24 December 2014

Received in revised form 25 February 2015

Accepted 25 March 2015

Available online 2 April 2015

\section{Keywords:}

Corpus luteum

Progesterone

Diestrus

Blood flow

Doppler ultrasonography

\begin{abstract}
A B S T R A C T
Human chorionic gonadotropin (hCG) has been used to induce ovulation and as a luteotrophic agent in cattle. However, the effect of hCG therapy on the functional status of the equine corpus luteum $(\mathrm{CL})$ is unclear. This study aimed to characterize the hemodynamic and secretory function of early CL of mares treated with different doses of hCG at distinct stages of the estrous cycle. Mares were assigned to nine experimental groups ( $n=6$ mares) group) according to dose of hCG and time of treatment. A single injection of one of three different doses of hCG $(750,1,500$, or $2,500 \mathrm{IU})$ was performed in one of three distinct stages of the estrous cycle: preovulatory follicle $\geq 35 \mathrm{~mm}$, day of ovulation (D0), or 48 hours after ovulation (D2). In addition, a control group treated with $\mathrm{NaCl} 0.9 \%$ was included in the study. The end points evaluated daily from D0 to D8 were area of the CL, luteal vascularity, number of colored pixels and total pixel intensity, and concentrations of plasma progesterone (P4). No effect $(P>.1)$ of dose or time of treatment was observed for any end point, within each day. Luteal area did not differ throughout the days $(P>.1)$, whereas Doppler parameters and concentrations of plasma P4 presented a progressive increase $(P<.05)$ after ovulation in all groups. Secretory function and luteal hemodynamic were not affected $(P>.1)$ by hCG dose and time of treatment. In conclusion, hCG therapy during estrus or early diestrus, at the doses tested, did not improve P4 secretion or luteal blood flow.
\end{abstract}

(c) 2015 Elsevier Inc. All rights reserved.

\section{Introduction}

The corpus luteum (CL) is a transient endocrine gland responsible for synthesis of progesterone (P4). Physiological functionality of this dynamic structure requires a

\footnotetext{
* Corresponding author at: Jair Camargo Ferreira, Department of Animal Reproduction and Veterinary Radiology, School of Veterinary Medicine and Animal Science, UNESP, 18618-970 Botucatu, SP, Brazil.

E-mail address: jaircfvet@yahoo.com.br (J.C. Ferreira).
}

prompt development of an extensive vascular network [1] that needs intense and progressive luteal angiogenesis during early diestrus [2].

Color Doppler ultrasonography is a noninvasive real-time pulse-wave technique currently used for transrectal study of hemodynamics of the reproductive system in large animals [1]. Considering the extensive luteal angiogenesis observed during early diestrus, Doppler ultrasonography has proven to be an efficient real-time method for in vivo evaluation of structural and functional status of the CL in mares [3]. 
Luteinizing hormone (LH) is essential for the luteogenic process and adequate function of the CL [4]. Human chorionic gonadotropin (hCG) is a glycoprotein with LH-like biological activity and luteotrophic action [5]. In cattle, hCG has been used to trigger a long-term rise in P4 [6,7], however, usually as a result of the formation of an accessory CL $[8,9]$. In mares, in vivo and in vitro studies suggested a positive correlation between hCG administration, concentrations of plasma P4, and fertility $[10,11]$. Conversely, Urquieta et al [12] and Hendriks et al [13] reported no effect of hCG therapy during estrus and early diestrus on future CL functionality.

As maturation of luteal cells in the newly formed $\mathrm{CL}$ is completed approximately 3-4 days after ovulation [3], treating mares with hCG to induce ovulation may have the potential to enhance luteal function. Therefore, considering the unclear effect of hCG on equine CL functionally, the effect of hCG therapy on P4 synthesis and luteal angiogenesis must be clarified.

Therefore, we have hypothesized that hCG therapy in the presence of a preovulatory follicle or at the day of ovulation, or 2 days after ovulation, would alter P4 secretion in mares. Accordingly, the main purpose of this study was to characterize the hemodynamic and secretory function of early CL of mares treated with different doses of hCG at distinct stages of the estrous cycle. Specific goals were to determine the temporal relationship between luteal blood flow, area of the CL, and concentrations of plasma P4 of mares treated with hCG.

\section{Material and Methods}

\subsection{Animals and Experimental Groups}

Cycling mixed breed mares 4-18 years of age, weighing 250-380 kg, were used. Animal care was carried out according to the São Paulo State University Guide for Care and Use of Agricultural Animals in Research. Mares were fed grass hay, pelleted feed, and trace-mineralized salt with free access to water. Body condition score for all mares was $>7$ (of 14 points; [14]). Age of mares was estimated from dental characteristics as described by the American Association of Equine Practitioners Manual [15]. Mares were scanned daily for follicular development monitoring and ovulation detection using B-mode ultrasonography.

Before the beginning of the experiment, all mares were submitted to ovulation inducing treatment with 2,500 IU of hCG to identify animals with refractory responses to hCG therapy. Only mares that ovulated between 24 and 48 hours after treatment with hCG were used.

Mares were assigned to nine experimental groups $(n=6$ mares/group) according to time of treatment and dose of hCG. Treatments were performed in one of three distinct stages of the estrous cycle: (a) when a dominant follicle $\geq 35 \mathrm{~mm}$ and uterine edema were observed (induction group); (b) on the day of ovulation (D0 group); or (c) 48 hours after ovulation detection (D2 group). A single IV injection of one of three different doses of hCG was used: $750,1,500$, or 2,500 IU (Vetecor 5000 U.I.; Calier S.A, Barcelona, Spain).

A control group of non-hCG-treated mares $(n=6)$ was included in the experimental approach. Mares from the control group were treated with a single IV injection of $2 \mathrm{~mL}$ of $0.9 \% \mathrm{NaCl}$ solution when a preovulatory follicle $\geq 35 \mathrm{~mm}$ associated with uterine edema was observed. Only mares with spontaneous ovulation were used in control, D0, and D2 groups. Transrectal ultrasonography examination was done once daily for monitoring of follicular development and detection of ovulation in D0 and D2 groups. In induction group, ultrasonography examination was performed every 6 hours from the moment of hCG treatment until the observation of a CL.

\subsection{Ultrasonography}

Doppler ultrasonography examination was performed every day from D0 to D8. Color Doppler ultrasound (Sonoace Pico; Medison do Brasil Ltda) equipped with a linear-array multifrequency transducer (LV5-9CDn, 5-9 MHz) was used for evaluation of vascular perfusion of the CL. Brightness, contrast, and gain settings of the ultrasound unit were kept constant throughout the experiment [16].

Power Doppler function was used to display blood flow signals in the luteal tissue as previously described by Ginther et al [17]. Vascular perfusion of the CL was initially estimated subjectively by considering the percentage $(0 \%-$ $100 \%)$ of luteal tissue with color Doppler signals during

Table 1

Mean ( \pm standard error of the mean) for follicle diameter $(\mathrm{mm})$ on the last ultrasonography examination before ovulation detection, luteal area (mm ${ }^{2}$ ) between D0 and D8, and concentration of plasma progesterone (ng/mL) on D8 in mares treated with 2,500, 1,500, or 750 IU of hCG ( $=6$ mares/group).

\begin{tabular}{lll}
\hline Groups & End Point & \\
\cline { 2 - 3 } & Follicle Diameter & Luteal Area \\
\hline Induction-750 & $35.7 \pm 0.58^{\mathrm{a}}(35.0-37.8)$ & $616.4 \pm 62.6(577.2-658.2)$ \\
Induction-1500 & $35.8 \pm 0.5^{\mathrm{a}}(35.0-39.1)$ & $566.3 \pm 45.3(487.3-614.0)$ \\
Induction-2500 & $35.8 \pm 0.6^{\mathrm{a}}(35.0-37.6)$ & $562.6 \pm 67.3(415.1-686.9)$ \\
D0-750 & $44.4 \pm 2.2^{\mathrm{b}}(50.0-52.9)$ & $613.9 \pm 49.8(473.5-700.6)$ \\
D0-1500 & $45.1 \pm 2.5^{\mathrm{b}}(38.9-53.0)$ & $627.9 \pm 68.3(571.9-672.1)$ \\
D0-2500 & $46.4 \pm 1.6^{\mathrm{b}}(41.1-51.0)$ & $598.9 \pm 71.0(491.4-708.1)$ \\
D2-750 & $44.1 \pm 1.3^{\mathrm{b}}(41.8-49.0)$ & $529.7 \pm 53.6(452.1-591.8)$ \\
D2-1500 & $43.5 \pm 1.0^{\mathrm{b}}(41.6-47.9)$ & $528.5 \pm 45.8(472.6-595.1)$ \\
D2-2500 & $45.4 \pm 2.8^{\mathrm{b}}(39.4-54.1)$ & $544.2 \pm 71.5(499,4-596.3)$ \\
\hline
\end{tabular}

Abbreviation: hCG, human chorionic gonadotropin.

Treatments have been performed in the presence of a preovulatory follicle $>35 \mathrm{~mm}$, on the first day of corpus luteum visualization or 2 days after ovulation (induction, D0, and D2 groups, respectively).

a,b are different $(P<.05)$ within an end point. 

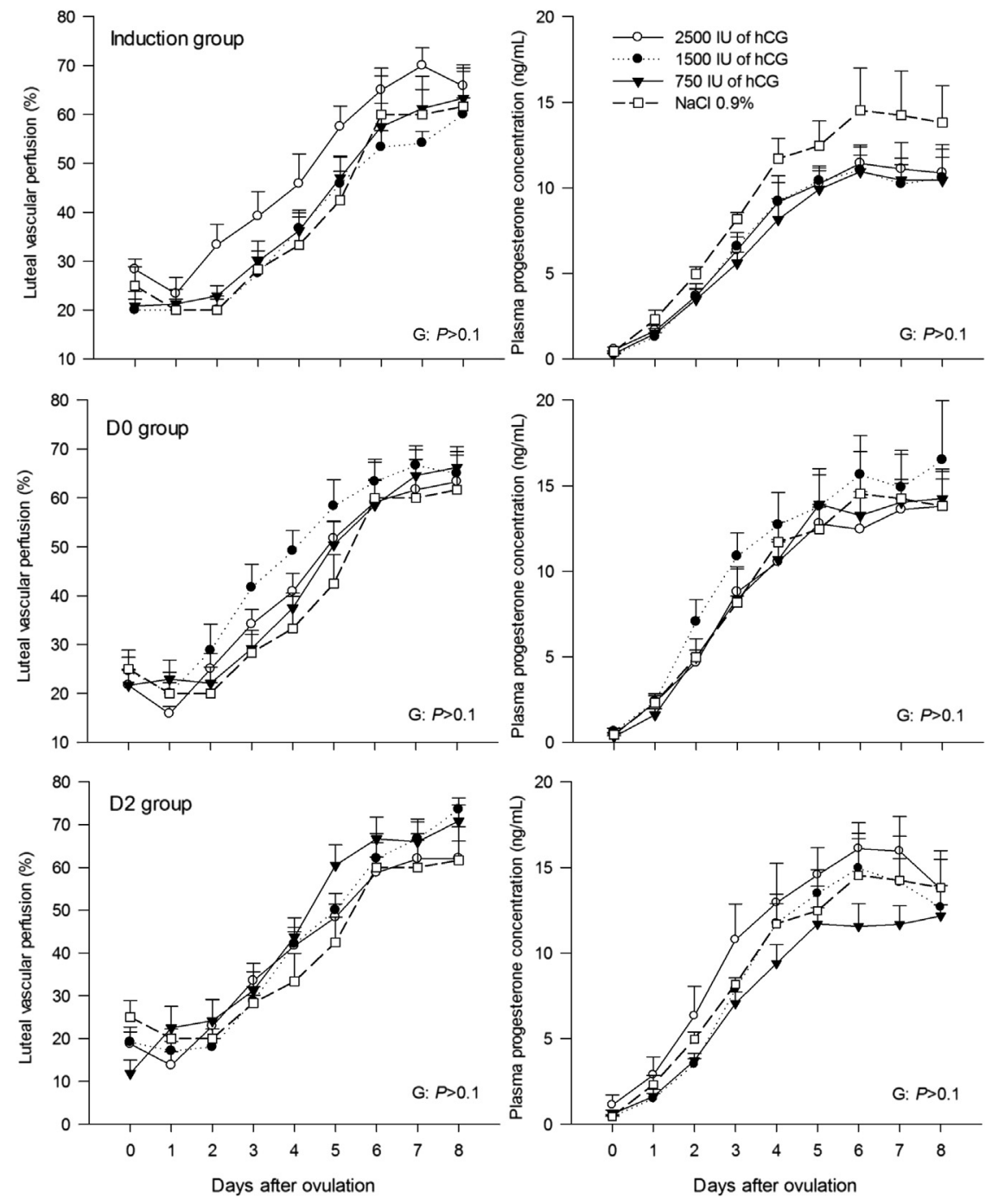

Fig. 1. Mean ( \pm standard error of the mean) for luteal vascular perfusion (\%) and concentrations of plasma P4 (ng/mL) of mares treated with $2,500,1,500,750 \mathrm{IU}$ of hCG ( $\mathrm{n}=6$ mares/group) or $2 \mathrm{~mL}$ of $\mathrm{NaCl} 0.9 \%$ in distinct stages of the estrous cycle. Single treatments have been performed in the presence of a preovulatory follicle $>35 \mathrm{~mm}$ associated with uterine edema, on the first day of CL visualization or 2 days after ovulation (induction, D0, and D2 groups, respectively). Probabilities for effect of group $(G)$ are shown. No effect of hCG dose within each day was observed $(P>.1)$ in induction, D0, and D2 groups. Abbreviations: CL, corpus luteum; hCG, human chorionic gonadotropin.

real-time imaging and continuous examination with a minimal of 1 -minute scan. Recorded data underwent objective evaluation to validate the subjective analysis. All Power Doppler scans were recorded on a laptop computer equipped with a video capture card (Pinnacle Studio 9). Three still images from cross-sections of the middle segment of the CL on each examination were extracted and saved in JPG and later TIFF format, using the software "Free Video to JPG converter v.5.0.22" and Adobe PhotoShop 5.5 (TIFF format, Adobe Systems, San Jose, CA). Number of luteal color Doppler signals was indicated by the total number and intensity of pixels per colored image which are calculated by the software Image $1.31 \mathrm{v}$ (National Institutes of Health, Bethesda, MD) as previously described [18]. Doppler intensity indicates the greater blood velocity considering the degree of brightness of the colored pixels [1]. Total pixel intensity of the $\mathrm{CL}$ was based on the computer-generated brightness level for each pixel, summed for all pixels [19].

The area of the $\mathrm{CL}\left(\mathrm{mm}^{2}\right)$ was determined using the scanner's tracing function, in one B-mode still image. In case of cavity CL, the luteinized area was calculated subtracting the cavity area from the total CL area.

\subsection{Progesterone Assay}

Blood samples were collected immediately before each ultrasonography examination by jugular venipuncture into heparinized tubes for the measurement of concentrations of plasma P4. After collection, samples were centrifuged $(1,200 \mathrm{~g}$ for 10 minutes). Plasma samples were stored at $-20^{\circ} \mathrm{C}$ until assayed. Concentrations of plasma P4 were measured using radioimmunoassay with commercial kit (Coat-a-count progesterone Kit, Diagnostic Product 

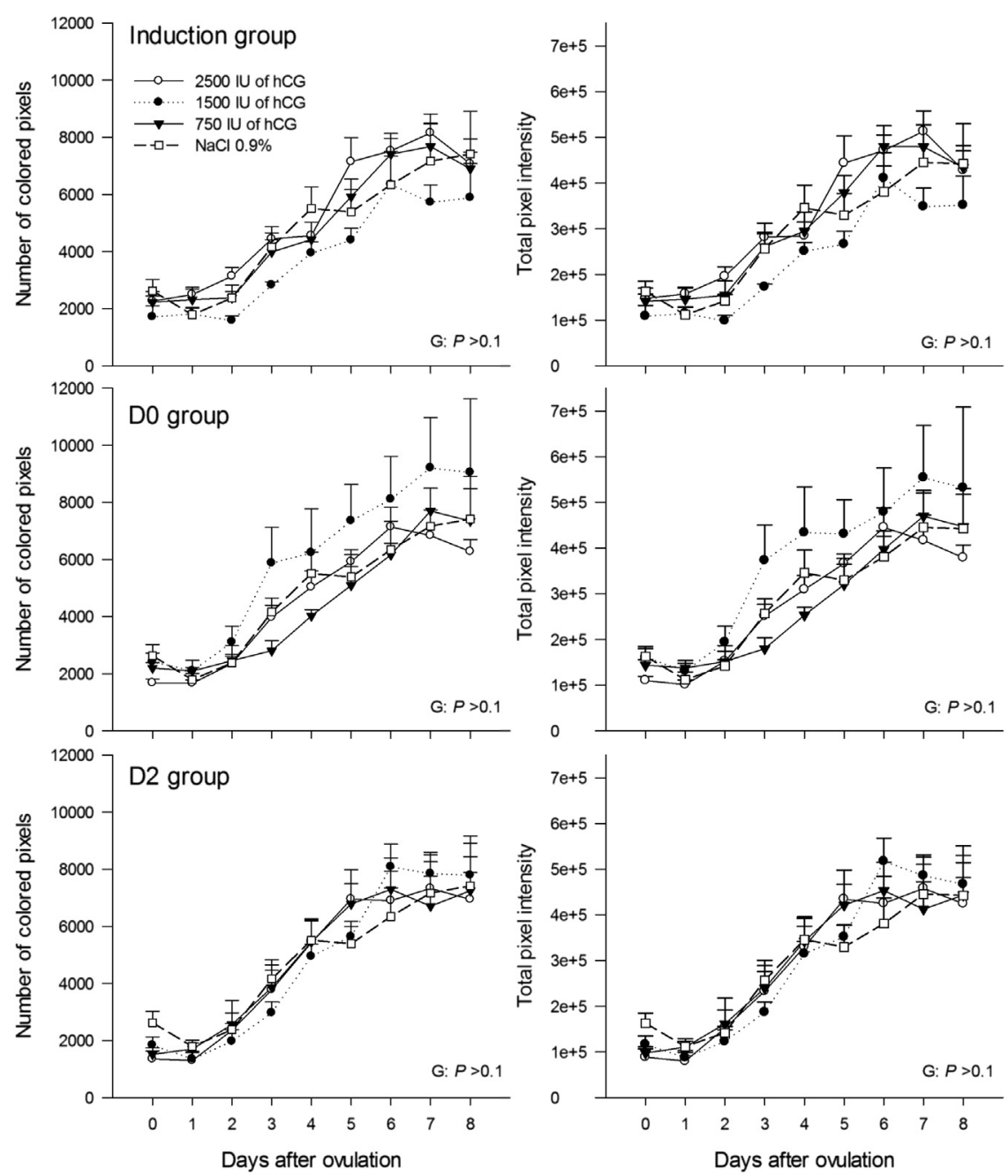

Fig. 2. Mean ( \pm standard error of the mean) for number of colored pixels and total pixel intensity of mares treated with $2,500,1,500,750$ IU of hCG ( $\mathrm{n}=6$ mares/ group) or $2 \mathrm{~mL}$ of $\mathrm{NaCl} 0.9 \%$ in distinct stages of the estrous cycle. Single treatments have been performed in the presence of a preovulatory follicle associated with uterine edema, on the first day of CL visualization or 2 days after ovulation (induction, D0, and D2 groups, respectively). Probabilities for effect of group (G) are shown. No effect of dose was observed $(P>.1)$. Abbreviations: CL, corpus luteum; hCG, human chorionic gonadotropin.

Corporation, DPC, Los Angeles, CA). The intraassay coefficient of variation and sensitivity of assay was $7.6 \pm 0.7 \%$ and $0.05 \mathrm{ng} / \mathrm{mL}$, respectively.

\subsection{Statistical Analyses}

Mixed-model analysis for repeated measures was used to compare the means of each response variable between groups and time and their interaction (SAS PROC MIXED Version 9.2 SAS Institute, Inc, Cary, NC). Post hoc analyses were conducted using Tukey test. The level of significance was defined at 0.05 . Data are present as mean \pm standard error of the mean.

\section{Results}

There was no effect of different doses of hCG administration on time of ovulation $(P>.1)$. Regardless of the dose of hCG, ovulation was detected approximately at
$41.0 \pm 1.0,38.0 \pm 2.0$, and $41.0 \pm 1.9$ hours after treatment with 2,500, 1,500, and 750 IU of hCG, respectively. When compared with hCG-treated mares independent of the dose, the interval between $0.9 \% \mathrm{NaCl}$ treatment and ovulation detection was greater $(P<.05)$ in control mares (105.6 \pm 14.0 hours). Follicle diameter on the last ultrasonography examination before ovulation detection of induced mares was smaller $(P<.05)$ than in mares with spontaneous ovulation from D0 and D2 groups (Table 1).

No effect $(P>1)$ of hCG dose or time of treatment was observed for area of the CL within each day. When compared with the control group $\left(603.0 \pm 104.8 \mathrm{~mm}^{2}\right.$, ranged from 506.5 to $668.6 \mathrm{~mm}^{2}$ ), the luteal area did not differ throughout the days in all treated groups, independently of the hCG dose and time of treatment (Table 1).

No effect of hCG dose was observed $(P>.1)$ for luteal vascular perfusion and concentrations of plasma $\mathrm{P} 4$ within induction, D0, and D2 groups (Fig. 1). Similarly, number of 

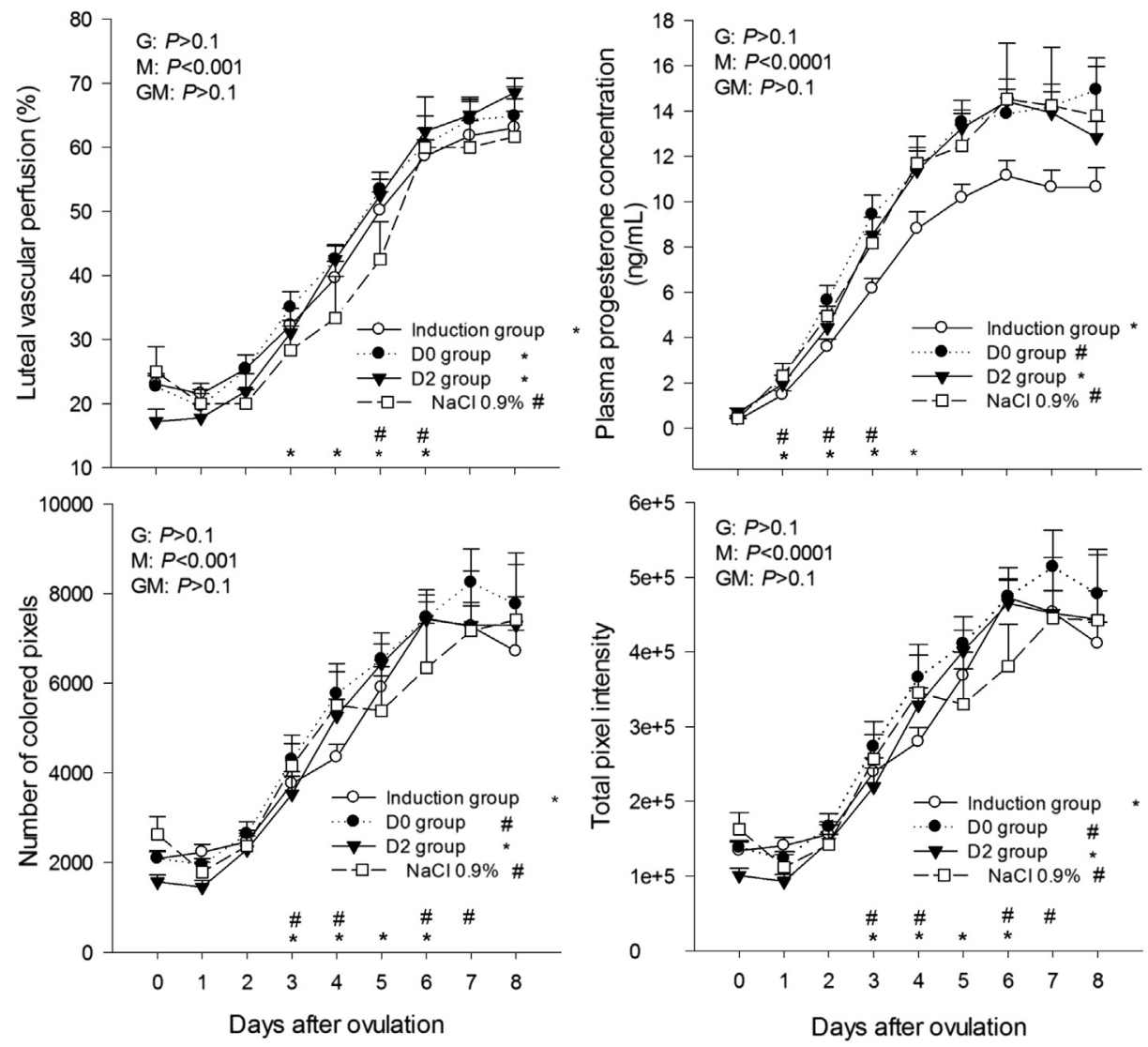

Fig. 3. Mean ( \pm standard error of the mean) luteal vascular perfusion (\%), concentrations of plasma P4 (ng/mL), number of colored pixels and total pixel intensity of mares treated with $2,500,1,500,750$ IU of hCG $(n=18$ mares/group), or $2 \mathrm{~mL}$ of $\mathrm{NaCl} 0.9 \%(n=6)$ in distinct stages of the estrous cycle. Single treatments have been performed in the presence of a preovulatory follicle associated with uterine edema, on the first day of CL visualization or 2 days after ovulation (induction, D0, and D2 groups, respectively). Probabilities for effect of group (G) and moment (M) and the interaction (GM) are shown. Significant and progressive increase of all end points was observed throughout days in all experimental groups. Symbols ( ${ }^{*}$ and \#) indicate statistical difference from previous day within the respective group. Abbreviation: CL, corpus luteum.

colored pixels and total pixel intensity were not affected $(P>.1)$ by hCG dose (Fig. 2).

Given that hCG dose did not affect the concentrations of plasma P4 and the Doppler parameters, data from all mares treated with different doses of hCG were pooled to evaluate the effect of time of hCG treatment on luteal function. Therefore, hCG-treated mares were divided into induction, D0, or D2 groups ( $\mathrm{n}=18$ mares/group). When compared with control group, no effect of time of treatment $(P>.1)$ was observed for concentrations of plasma P4, luteal vascular perfusion, number of colored pixels, or total pixel intensity (Fig. 3).

A progressive increase on vascular perfusion of the $\mathrm{CL}$ and concentrations of plasma P4 was observed in all experimental groups $(P<.001)$. Number of colored pixels and total pixel intensity also increased $(P<.001)$ during the first 8 days after ovulation.

Area of the CL was weakly correlated with subjective luteal vascular perfusion $(r=-0.14 ; P<.0001)$ and concentrations of plasma $\mathrm{P} 4(r=0.12 ; P<.0001)$. A positive correlation $(r=0.69 ; P<.0001)$ was observed between subjective luteal vascular perfusion and concentrations of plasma P4 (Fig. 4). Similarly, number of colored pixels and total pixel intensity were positively correlated with the subjective luteal vascular perfusion ( $r=0.82$ and $r=0.81$, respectively; $P<$ $.0001)$ and with concentrations of plasma P4 concentration $(r=0.77$ and $r=0.75$, respectively; $P<.0001)$.

\section{Discussion}

The findings of the present study demonstrated no effect of hCG, independent of dose and time of treatment, on the functional and structural status of the $\mathrm{CL}$ in mares. Secretion of P4 was not affected by hCG therapy, which is in contrast to the report recently for cattle $[8,9]$. In addition, luteal hemodynamic of mares treated with low doses of hCG during estrus and early diestrus was characterized for the first time.

Our findings showed that follicle diameter does not affect directly the subsequent luteal function in mares. Although hCG-treated mares had smaller follicle diameter during the last examination before ovulation detection when compared with spontaneous ovulating mares, no difference was found between groups for area of the CL, concentrations of plasma $\mathrm{P} 4$, or luteal Doppler parameters during the first 8 days of diestrus. In contrast to what has 


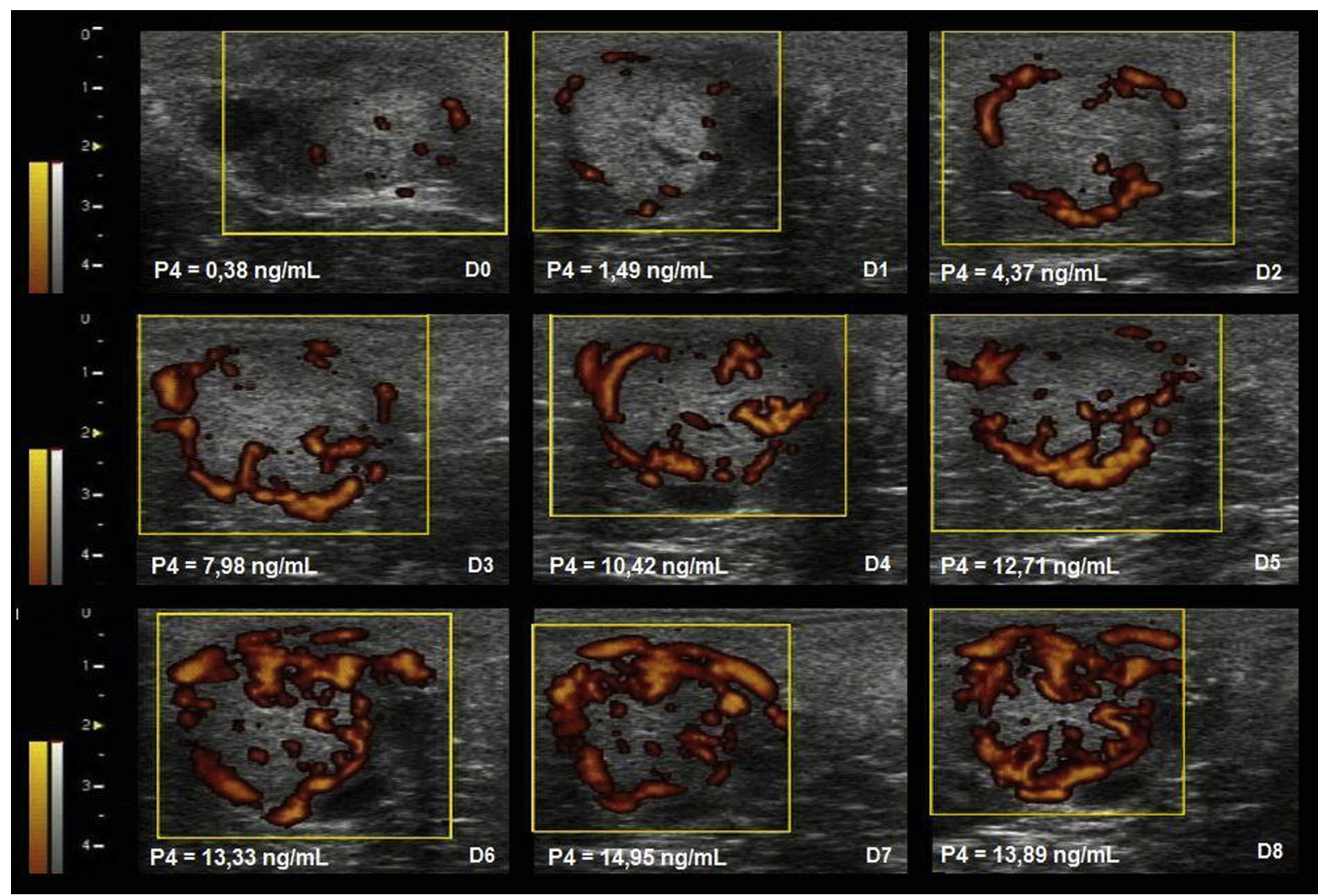

Fig. 4. Colored power-flow Doppler sonograms of equine CL during early diestrus. Day of estrous cycle (D0 = day of ovulation) and respective concentrations of plasma P4 are shown. Subjective vascular perfusion of the CL (\%) was scored according to the extent of luteal tissue with colored Doppler signals in the luteinized area. Abbreviation: CL, corpus luteum.

been described in cattle [7], ovulation inducing treatment with hCG is able to trigger a cascade of events that result in the ovulation process in mares [20] without improvement of secretory function of the CL.

Low doses of hCG were just as effective in inducing ovulation within 48 hours after treatment such as high doses of hCG, as previously reported [21]. In contrast to the suggestion by Fleury et al [11], a supposed beneficial effect on luteal P4 synthesis as a consequence of hCG action when used to induce ovulation was not observed. Moreover, morphometric parameters and functional status of CLs originated from ovulation inducting treatments with low doses ( 750 or 1,500 IU of hCG) were similar to the observed in mares treated with 2,500 IU of hCG or with spontaneous ovulation. In nonpregnant mares, the posttreatment luteal function has not been affected by the superovulatory treatment with equine LH during diestrus [22]. In addition, the progestin secretion during the first days after ovulation has not been affected by the treatment with hCG for induction of ovulation in pregnant mares [23]. Therefore, the hypothesis that hCG therapy during estrus or early diestrus does not affect P4 releasing was supported.

The progressive increase on concentrations of plasma P4 and high positive correlation with Doppler parameters is in agreement with previous reports in mares with spontaneous ovulation $[17,24]$. Moreover, no changes on uterine artery blood flow indices after the treatment with hCG have been recently reported in mares [25]. The prompt endothelial cell proliferation with the establishment of a dense capillary network establishment occurs during early phase and is required for synthesis and secretion of P4 [2,26,27].

It is likely that the physiological response of hCG action on luteal angiogenesis and, consequently, P4 synthesis differs between equine and bovine species. In the present study, an immediate and long-term rise in P4 associated with a temporary elevation of luteal vascular perfusion was not observed as previously reported in cattle [7]. Moreover, the formation of an accessory CL did not occur in the mares between D0 and D8, independent of the hCG dose and time of treatment. Greater concentrations of plasma P4 associated with greater incidence of secondary ovulations during the diestrus have been observed in cows treated with hCG $[8,9]$. However, the overall effect of hCG treatment on pregnant rate of cattle is remain unclear [28,29].

An earlier luteogenesis in mares treated with hCG 1 day after ovulation has been suggested [11]. However, the present study demonstrated no effect of hCG on the luteal secretory function when administrated on the day of $\mathrm{CL}$ detection or 2 days after ovulation. Moreover, the secretory activity of CL was not correlated with its area in the present study. This finding is in agreement with a previous study that found no correlation between luteal diameter and ovarian blood flow in mares [22]. The high positive correlation observed between concentrations of plasma P4 and 
luteal vascular perfusion associated with an absence of $\mathrm{CL}$ area changes during the experiment suggests that Doppler technology may be a more effective method than conventional ultrasonography for evaluation of luteal functionality.

\section{Conclusions}

Under the current experimental conditions, hCG therapy during estrus and early diestrus did not improve luteal blood flow and P4 synthesis in mares. Moreover, the area of the primary CL and the incidence of accessory CL were not affected by administration of hCG, regardless of dose.

\section{Acknowledgments}

This research was financially supported by Fapesp (Grant \#2011/04744-9, 2012/05790-7).

\section{References}

[1] Ginther OJ. Ultrasonic imaging and animal reproduction: colorDoppler ultrasonography. 1st ed. Cross Plains: Equiservices; 2007.

[2] Alziabi MO, Watson ED, Fraser HM. Angiogenesis and vascular endothelial growth factor expression in the equine corpus luteum. Reproduction 2003;125:259-70.

[3] Bergfelt DR, Adams GP. Luteal development. In: McKinnon AO, Squires EL, Vaala WE, Varner DD, editors. Equine Reproduction. 2nd ed. Wiley Blackwell; 2011. p. 2055-64.

[4] Niswender GD, Juengel JL, Silva PJ, Rollyson MK, Mcintush EW. Mechanisms controlling the function and life span of the corpus luteum. Physiol Rev 2000;80:1-29.

[5] Newcombe JR. Human chorionic gonadotropin. In: McKinnon AO, Squires EL, Vaala WE, Varner DD, editors. Equine Reproduction. 2nd ed. Wiley Blackwell; 2011. p. p.1804-10.

[6] Rensis F, Valentini R, Gorrieri F, Bottarelli E, Lopez-gatius F. Inducing ovulation with hCG improves the fertility of dairy cows during the warm season. Theriogenology 2008;69:1077-82.

[7] Beindorff N, Honnens A, Penno Y, Paul V, Bollwein H. Effects of human chorionic gonadotropin on luteal blood flow and progesterone secretion in cows and in vitro-microdialyzed corpora lutea. Theriogenology 2009;72:528-34.

[8] Rajamahendran R, Sianangama PC. Effect of human chorionic gonadotropin on dominant follicles in cows: formation of accessory corpora lutea, progesterone production and pregnancy rates. J Reprod Fert 1992;92:577-84.

[9] Rizos D, Scully S, Kelly AK, Ealy AD, Moros R, Duffy P, Naib AA, Forde N, Lonergan P. Effects of human chorionic gonadotropin administration on day 5 after oestrus on corpus luteum characteristics, circulating progesterone and conceptus elongation in cattle. Reprod Fertil Dev 2012;24:472-81.

[10] Kelly CM, Hoyer PB, Wise ME. In vitro and in vivo responsiveness of the corpus luteum of the mare to gonadotropin stimulation. J Reprod Fertil 1988;84:593-600.
[11] Fleury PDC, Alonso MA, Sousa FAC, Andrade AFC, Arruda RP. Use of hCG to improve the reproductive characteristics and fertility in recipients mares. Rev Bras Reprod Anim 2007;31:27-31.

[12] Urquieta B, Duran MC, Coloma I, Parraguez VH. hCG induced ovulation in Thoroughbred mares does not affect corpus luteum development and function during early pregnancy. Reprod Domest Anim 2009;44:859-64.

[13] Hendriks WK, Colenbrander B, Stout TAE. Effect of administering PGF2 or hCG on day 7 after ovulation on ovarian, uterine and luteal blood flow in the mare. Anim Reprod Sci 2006;94:223-5.

[14] Henneke DR, Potter GD, Kreider JL, Yeates BF. Relationship between condition score, physical measurements and body fat percentage in mares. Equine Vet J 1983;15:371-2.

[15] American Association of Equine Practitioners Manual. Official guide for determining the age of the horse. Lexington, KY: AAEP; 2002.

[16] Gastal EL, Gastal MO, Ginther OJ. The suitability of echotexture characteristics of the follicular wall for identifying the optimal breeding day in mares. Theriogenology 1998;50:1025-38.

[17] Ginther OJ, Gastal EL, Gastal MO, Utt MD, Beg MA. Luteal blood flow and progesterone production in mares. Anim Reprod Sci 2007;99: 213-20.

[18] Ginther OJ, Utt MD. Doppler ultrasound in equine reproduction: principles, techniques, and potential. J Equine Vet Sci 2004;24: $516-26$.

[19] Silva LA, Ginther OJ. Local effect of the conceptus on uterine vascular perfusion during early pregnancy in heifers. Reproduction 2010; 139:453-63.

[20] Richards JS, Russel DL, Ochsner S, Espey LL. Ovulation: new dimension and new regulators of the inflammatory-like response. Annu Rev Physiol 2002;64:69-92.

[21] Gastal EL, Silva LA, Gastal MO, Evans MJ. Effect of different doses of hCG on diameter of the preovulatory follicle and interval to ovulation in mares. Anim Reprod Sci 2006;94:186-90.

[22] Schauer SN, Guillaume D, Decourt C, Watson ED, Briant C, Donadeu FX. Effect of luteinizing hormone overstimulation on equine follicle maturation. Theriogenology 2013;79:409-16.

[23] Köhnea M, Kuhlb J, Illec N, Erberb R, Aurich C. Treatment with human chorionic gonadotropin before ovulation increases progestin concentration in early equine pregnancies. Anim Reprod Sci 2014; 149:187-93.

[24] Bollwein H, Mayer R, Weber F, Stolla R. Luteal blood flow during cycle in mares. Theriogenology 2002;65:2043-51.

[25] Yilmaz OT, Gunduz MC, Dal GE, Kurban I, Erzengin OM, Ucmak M. Is uterine blood flow influenced by hCG and mare age? Anim Reprod Sci 2014;151:182-5.

[26] Ginther OJ. Reproductive biology of the mare, basic and applied aspects. 2nd ed. WI: Equiservices Publishing; 1992.

[27] Ferreira-Dias G, Pinto-Bravo P, Mateus L, Redmerc DA, Medeiros JA Microvascularization and angiogenic activity of equine corpora lutea throughout the estrous cycle. Domest Anim Endocrinol 2006; 30:247-59.

[28] Santos JEP, Thatcher WW, Pool L, Overton MW. Effect of human chorionic gonadotropin on luteal function and reproductive performance of high-producing lactating Holstein dairy cows. J Anim Sci 2001;79:2881-94.

[29] King SG, Dobson H, Royal MD, Christley RM, Murray RD, Routly JE, Smith RF, Mann GE. Identification of inadequate maternal progesterone concentrations in nulliparous dairy heifers and treatment with human chorionic gonadotrophin. Vet Rec 2013;173:450. 